\title{
PRONOMES RESUMPTIVOS EM PORTUGUÊS BRASILEIRO INFANTIL: DADOS DE PRODUÇÃO E COMPREENSÃO
}

\author{
Elaine Grolla \\ Marina R.A. Augusto
}

\begin{abstract}
RESUMO
Este artigo apresenta os resultados de três estudos que investigaram a produção e a compreensão de pronomes resumptivos (PRs) por crianças e adultos falantes de português brasileiro (PB) como língua materna. PRs em diversas posiçooes sintáticas foram testados e os resultados sugerem que seu uso em PB é limitado, parecendo estar condicionado à posição sintática de extração.
\end{abstract}

PALAVRAS-CHAVE: oraçóes relativas; estruturas de tópico-comentáro; pronomes resumptivos; lacunas; métodos experimentais.

\section{Introdução}

ste estudo faz parte de uma investigação mais ampla que busca caracterizar a produção e compreensão de pronomes resumptivos (PRs) na aquisição do português brasileiro (PB) como língua materna. Neste artigo, apresentam-se os resultados de três estudos que investigaram a produção de PRs no contexto de oraçóes relativas em diversas posiçóes sintáticas e a compreensão de PRs em estruturas de tópico-comentário de objeto direto. Nos exemplos seguintes, temos PRs na posição de sujeito (1a), objeto direto (1b) e genitivo (1c) em oraçóes relativas: 
$\searrow \nleftarrow$ a. Eu escolhi o macaco que ele está comendo milho.

b. Eu escolhi o milho que o macaco está comendo ele.

c. Eu escolhi o carro que o menino está lavando o pneu dele.

Adultos falantes de PB tendem a não produzir PRs em oraçóes relativas, ao passo que as crianças as produzem em certa medida, como será exposto a seguir. As crianças produzem PRs em oraçôes relativas, mas seu comportamento no teste de julgamento de valor de verdade, com estruturas tópico-comentário, é revelador. Comparando-se estruturas com e sem PRs, observamos que os PRs não parecem facilitar sua compreensão, se comparadas com as que não possuem PRs.

No que se segue, discutimos os resultados de estudos anteriores sobre a aquisição de PRs em diversas línguas (seção 1). Depois, apresentamos os resultados dos três experimentos mencionados, conduzidos com falantes de PB (seção 2). A seção 3 traz uma discussão sobre os resultados obtidos. A seção 4 apresenta as conclusóes do trabalho.

\section{Pronomes resumptivos na aquisição da linguagem}

Pesquisas sobre a aquisição de pronomes resumptivos (PRs) mostram que crianças adquirindo línguas como inglês, francês, espanhol, servo-croata, hebraico, português brasileiro e russo produzem ou julgam gramaticais oraçôes relativas contendo tais pronomes em diversas posições sintáticas, algumas vezes violando restriçóes encontradas nas línguas adultas. No que se segue, elencaremos uma série de estudos que investigaram o comportamento das crianças com relação a esses pronomes, a fim de fornecer um panorama geral acerca da aquisição de PRs nas mais diversas línguas.

O primeiro estudo a ser mencionado é o de Labelle (1988, 1990), que testou 108 crianças entre 3;0 e 6;0 anos de idade adquirindo francês como língua materna. A tarefa utilizada em seu estudo foi a de produção eliciada com auxílio de figuras (que as crianças tinham que descrever). Labelle (1988, 1990) reporta que as crianças produziram PRs nas posiçóes: sujeito, objeto direto e indireto, locativos e genitivos. Tais construçóes não são lícitas em francês adulto. Na tabela 1, fornecida a seguir, é possível visualizar as taxas de produção de PRs do estudo de Labelle, além das taxas obtidas nos estudos discutidos a seguir. 
Pérez-Leroux (1995) investigou a produção e compreensão de PRs em inglês e espanhol. Para o estudo de produção, foi utilizada a tarefa de produção eliciada, nos mesmos moldes de Labelle (1988). Onze crianças entre 3;5 e 5;5 adquirindo inglês e 26 crianças entre 3;5 e 6;8 adquirindo espanhol foram entrevistadas. Como reportado na tabela 1 , muitas das produçóes infantis observadas não são lícitas nas línguas adultas.

Varlokosta e Armon-Lotem (1998) investigaram a produção de PRs em oraçôes relativas em crianças adquirindo grego moderno e hebraico. O experimento era uma tarefa de produção eliciada com auxílio de brinquedos. Foram entrevistadas 13 crianças adquirindo grego entre 3;0 e 5;6 anos e 24 crianças adquirindo hebraico entre 2;8 e 5;5 anos de idade. As crianças adquirindo grego produziram PRs nas posiçóes de objeto direto e indireto e como complemento de preposição. Todas essas construçôes são lícitas na língua adulta. No entanto, para o hebraico, os autores obtiveram 24\% de produção de PRs em posição de sujeito, algo inaceitável em hebraico adulto. Para as outras posiçóes sintáticas testadas, as crianças produziram PRs, de acordo com o que é encontrado na língua adulta, como pode ser visto na tabela 1 a seguir.

Grolla (2004) conduziu um experimento com 11 crianças adquirindo PB como língua materna entre 3;0 e 5;5 anos de idade. Uma tarefa de julgamento de gramaticalidade foi utilizada, em que a criança julgava como gramatical ou não as sentenças proferidas por um fantoche. As crianças julgaram como gramaticais PRs em posição sujeito, objeto direto e oblíquo. Adultos não julgaram PRs em posição de sujeito como gramaticais.

A tabela 1 a seguir traz as taxas de produção de PRs nas diferentes posiçôes sintáticas testadas nos estudos mencionados anteriormente. Ela traz ainda as taxas de aceitação fornecidas pelas crianças do estudo de Grolla (2004) para o $\mathrm{PB}^{1}$ :

1 A quantidade de estudos sobre o tema é vasta. Está além do escopo deste artigo fazer um apanhado geral de todos eles. No entanto, citamos outros dois estudos relevantes. Um deles é o de Goodluck e Stojanovic (1996), que investigou o comportamento infantil acerca de PRs em servo-croata. As autoras testaram 42 crianças adquirindo servo-croata entre 4;0 e 6;0 anos de idade. Uma tarefa de produção eliciada com auxílio de figuras foi utilizada. Embora as autoras não tenham fornecido as percentagens exatas de produção de PRs, o gráfico apresentado mostra que as crianças produziram relativas de objeto direto, indireto e oblíquas e, em todas elas, PRs foram produzidos. Em diversos casos, os PRs não são lícitos na língua adulta. 


\begin{tabular}{|l|c|c|c|c|c|}
\hline Posiçăo $^{2}$ & \multicolumn{4}{|c|}{ Tarefas de Produçáo } & $\begin{array}{c}\text { Julgamentos de } \\
\text { Gramaticalidade }\end{array}$ \\
\hline & Inglêss $^{\mathrm{a}}$ & Espanhol $^{\mathrm{a}}$ & Francês $^{\mathrm{b}}$ & Hebraico & $\mathrm{PB}^{\mathrm{d}}$ \\
\hline Sujeito & - & - & ${ }^{*} 26,9 \%$ & $* 24 \%$ & $* 63 \%$ \\
\hline OD & $* 25 \%$ & $* 36,2 \%$ & $* 25 \%$ & $93 \%$ & $\% * 72 \%$ \\
\hline Oblíquo & $* 26,9 \%$ & $* 60 \%$ & $* 28 \%$ & $83 \%$ & $90 \%$ \\
\hline
\end{tabular}

Tabela 1: Taxas de produção e aceitação de pronomes resumptivos (PRs)

Um primeiro fato interessante mostrado na tabela é que as crianças não apresentam um comportamento adulto em suas produçóes de PRs e em seus julgamentos. Esse comportamento aparece em diversas línguas, sejam elas línguas em que PRs possuem uma distribuição mais restrita, como inglês, sejam línguas em que PRs são mais produtivos, como hebraico e PB. Em especial, crianças tendem a produzir e a aceitar PRs em posição de sujeito, algo impossível em todas as línguas testadas. Poderíamos caracterizar o comportamento das crianças como um caso de sobregeração e sobreaceitação, isto é, elas produzem e aceitam PRs em posições em que os adultos não os permitem.

No que se segue, discutiremos dois trabalhos que realizaram estudos comparativos. O primeiro deles é McKee e McDaniel (2001), que investigou a produção e compreensão de PRs em diversas posições sintáticas por crianças adquirindo inglês como língua materna em três estudos. Para o primeiro estudo, que tinha como foco a produção de oraçóes relativas de sujeito, as autoras entrevistaram 82 crianças entre 3;5 e 8;11 anos de idade. Para o segundo estudo, as autoras testaram 89 crianças entre 3;5 e 8;11. Esse segundo experimento objetivava a produçáo de relativas de objeto direto, objeto de preposição, genitivo sujeito e genitivo objeto. ${ }^{3} \mathrm{O}$ terceiro estudo, sobre compreensão, teve

2 Bar-Shalom e Vinnitskaya (2004) testaram 33 crianças adquirindo russo entre 4;0 e 6;10 anos de idade. As autoras observam que as crianças produziram relativas de objeto direto com PRs, embora na língua adulta eles não sejam possíveis nessa posição.

Estudos a partir dos quais tais taxas foram extraídas: a Pérez-Leroux (1995), b Labelle (1990), c Varlokosta e Armon-Lotem (1998) e d Grolla (2004). O asterisco na frente de uma porcentagem indica que um PR naquela posição é ilícito na língua adulta correspondente. $\mathrm{O}$ símbolo \% indica que o comportamento adulto não é uniforme, com adultos que consistentemente aceitam a estrutura e adultos que consistentemente a rejeitam, no que se configura em uma diferença dialetal.

3 Exemplos de sentenças usadas no estudo:

Sujeito: The elephant that it is flying. ( $O$ elefante que ele está voando) 
como método a tarefa de julgamento de gramaticalidade. Para esse estudo foram entrevistadas as mesmas crianças do primeiro estudo. Nesse experimento, 17 condiçôes foram testadas. Algumas delas possuíam PRs e outras não. As posiçôes sintáticas que mais nos interessam aqui são: sujeito, objeto direto, objeto de preposição, genitivo sujeito, genitivo objeto e sujeito não extraível. ${ }^{4}$ $\mathrm{Na}$ tabela 2 a seguir, listamos os resultados obtidos pelas autoras.

\begin{tabular}{|l|c|c|c|c|}
\hline \multicolumn{5}{|c|}{ McKee e McDaniel (2001) } \\
\hline Posição & \multicolumn{2}{|c|}{ Produção } & \multicolumn{2}{|c|}{ Julgamento de Gramaticalidade } \\
\hline & $\begin{array}{c}\text { Crianças } \\
(\mathrm{N}=89)\end{array}$ & $\begin{array}{c}\text { Adultos } \\
(\mathrm{N}=20)\end{array}$ & $\begin{array}{c}\text { Crianças } \\
(\mathrm{N}=82)\end{array}$ & $\begin{array}{c}\text { Adultos } \\
(\mathrm{N}=34)\end{array}$ \\
\hline Sujeito & $2 \%$ & $0 \%$ & $47 \%$ & $2 \%$ \\
\hline OD & $2 \%$ & $0 \%$ & $70 \%$ & $2 \%$ \\
\hline Oblíquo & $5 \%$ & $0 \%$ & $68 \%$ & $2 \%$ \\
\hline Genitivo Suj. & $18 \%$ & $2 \%$ & $50 \%$ & $25 \%$ \\
\hline Genitivo Obj. & $50 \%$ & $65 \%$ & $75 \%$ & $68 \%$ \\
\hline
\end{tabular}

Tabela 2: Taxas de produção e aceitação de pronomes resumptivos (PRs) no inglês

Vários fatos são dignos de nota. Em primeiro lugar, observamos que as crianças do estudo apresentam taxas de produção de PRs parecidas com as dos adultos para a maioria das posiçóes sintáticas, principalmente as extraíveis (sujeito, OD e oblíquo). Já com relação aos julgamentos de gramaticalidade, diferenças importantes podem ser vistas. Apenas para a posição de genitivo objeto é que as taxas de aceitação de adultos e crianças são comparáveis. As crianças tendem a ter altas taxas de aceitação para PRs em qualquer posição sintática, ao contrário dos adultos, que quase não os aceitam na grande maioria de posiçôes.

OD: The cat that Goofy is petting it. (O gato que o Pluto está acariciando ele)

Oblíquo:The girl that the giraffe is sitting on her. (A menina que a girafa está sentando em cima dela)

Genitivo Sujeito: The baby that her teddy bear is riding in the wagon. (O bebê que o ursinho dele está no trem)

Genitivo Objeto: The robber that Dorothy is swinging his rope. (O ladrão que a Dorothy está balançando a corda dele).

4 Para detalhes sobre todas as posiçôes sintáticas testadas, cf. McKee e McDaniel (2001). 
Outro fato interessante a se observar é que existe uma assimetria entre as taxas de aceitação e produção de PRs. As crianças julgam aceitáveis sentenças com PRs mais frequentemente do que produzem sentenças com PRs. No entanto, essa assimetria entre produção e julgamento de gramaticalidade não é surpreendente. Mesmo em línguas em que PRs são mais produtivos, não é o caso que eles sejam obrigatórios em todas as posições. $\mathrm{O}$ uso de PRs é opcional em algumas posiçóes sintáticas, e as crianças podem omiti-los de uma oração relativa pela mesma razão que falantes de hebraico, por exemplo, não os produzem $100 \%$ das vezes em posiçóes como objeto direto. Por outro lado, na tarefa de julgamento de gramaticalidade, as crianças devem dizer se uma construção com um PR é aceitável ou não. Portanto, toda vez que uma sentença com um PR é apresentada, elas têm a chance de dizer 'sim', aceitando a construção com o pronome.

Em Grolla (2010), é feito um estudo comparativo com crianças e adultos para o inglês e o $\mathrm{PB}$. O método é a tarefa de julgamento de gramaticalidade, e são duas as posiçôes sintáticas em investigação: posição mais alta de sujeito e sujeito dentro de ilhas. ${ }^{5}$ As 40 crianças entrevistadas falantes de PB tinham entre 3;4 e 6;6 anos de idade e as 23 falantes de inglês tinham entre 3;7 e 5;11 anos de idade. As taxas de aceitação são mostradas na tabela 3 a seguir:

\begin{tabular}{|l|c|c|c|c|}
\hline \multicolumn{5}{|c|}{ Tarefa de Julgamento de Gramaticalidade (Grolla 2005) } \\
\hline & \multicolumn{2}{|c|}{$\mathrm{PB}$} & \multicolumn{2}{c|}{ Inglês } \\
\hline \multirow{2}{*}{} & $\begin{array}{c}\text { Crianças } \\
(\mathrm{N}=40)\end{array}$ & $\begin{array}{c}\text { Adultos } \\
(\mathrm{N}=7)\end{array}$ & $\begin{array}{c}\text { Crianças } \\
(\mathrm{N}=23)\end{array}$ & $\begin{array}{c}\text { Adultos } \\
(\mathrm{N}=5)\end{array}$ \\
\hline Sujeito & $58,1 \%$ & $10.7 \%$ & $48.9 \%$ & $5 \%$ \\
\hline Ilha & $95 \%$ & $92.8 \%$ & $88 \%$ & $90 \%$ \\
\hline
\end{tabular}

Tabela 3: Taxas de aceitaçáo de pronomes resumptivos (PRs) no PB e no inglês

Podemos observar que o mesmo padrão de comportamento é encontrado nas duas línguas. As crianças diferem dos adultos ao aceitarem PRs em

5 As sentenças testadas foram:

Sujeito: *O sapo que ele está esquiando está contente./*The frog that he is skating is happy. Ilha: Esse é o sapo que o cisne riu quando ele caiu./ This is the frog that the swan laughed when he fell. 
posição de sujeito em um nível que pode ser descrito como de chance, mas apresentam comportamento similar aos adultos na posição dentro de ilhas, aceitando acima de $90 \%$ tais casos. Esses dados indicam que as crianças não aceitam PRs indistintamente: há uma diferença entre as taxas para as duas posições sintáticas.

Esse conjunto de dados de estudos anteriores indica que as crianças tendem a aceitar e a produzir PRs em posiçóes ilícitas nas línguas adultas sendo adquiridas. No entanto, tal comportamento não adulto é mais frequentemente encontrado em posiçóes extraíveis, como sujeito mais alto e objeto direto. Em posiçôes não extraíveis, o comportamento infantil se aproxima mais do comportamento adulto.

No que se segue, apresentamos novos resultados experimentais com crianças falantes de PB. Nosso objetivo geral nesse estudo é investigar o comportamento das crianças com relação à produção de orações relativas de sujeito, objeto direto e genitivo, além de observar seu comportamento em um teste de compreensão, envolvendo estruturas de tópico-comentário com ou sem PRs. Passemos a eles.

\section{Resultados experimentais em Português do Brasil}

Três experimentos conduzidos com crianças em idade pré-escolar serão reportados: os dois primeiros tratam da produção de estruturas relativas, e o último explora a compreensão de estruturas de tópico-comentário.

\subsection{Experimento 1: produção de relativas a partir de manipulação de brinquedos}

Nesse experimento, ${ }^{6}$ buscou-se verificar se crianças produzem PRs em sentenças relativas de objeto direto, eliciadas com base na observação de cenas a partir da manipulação de brinquedos pelo experimentador. A variável dependente do experimento é o número de produções da estrutura-alvo, ou seja, sentenças relativas e, dentre essas, o número de produções contendo PRs. A única variável independente manipulada foi idade (crianças e adultos, como grupo controle).

6 Os dados foram coletados durante o ano de 2010 e uma primeira análise dos resultados é apresentada em Pires \& Vivanco (2011). 


\section{Métodos:}

Participantes: Esse experimento foi aplicado a 21 crianças com idades entre 4;0 e 6;11 anos (idade média 4;8), sendo quatro crianças com idades entre 4;0 e 4;11, 19 crianças com idades entre 5;0 e 5;11 e duas crianças com idades entre $6 ; 0$ e 6;11. Nove adultos compuseram o grupo-controle.

\section{Material:}

Foram utilizados brinquedos de plástico para a manipulação/encenação de oito histórias. Um fantoche, de nome Caco, também era utilizado.

\section{Procedimento:}

As crianças eram convidadas a participar, individualmente, de uma atividade em uma sala isolada da escola. Um fantoche de nome Caco era apresentado e se dizia que eles iriam brincar com diversos brinquedos e ouvir histórias. Explicava-se que o fantoche teria seus olhos vendados e que a criança deveria ouvir as histórias e escolher um personagem ao final de cada uma. A seguir, a primeira história era encenada com alguns brinquedos, sendo que os dois personagens principais eram idênticos (dois macacos, por exemplo). Ao final, a criança era solicitada a escolher um dos brinquedos e contar ao fantoche Caco (que tinha os olhos vendados) qual tinha sido sua escolha. Como o fantoche náo podia ver os brinquedos, a criança não poderia simplesmente apontar para o brinquedo escolhido; era necessário dizer verbalmente sua escolha. Para distingui-lo do par idêntico, esperava-se que a criança usasse uma oração relativa. O procedimento todo, contando-se todas as oito histórias, durava 30 minutos. A seguir, ilustra-se uma das histórias ( $\mathrm{E}=$ experimentador; $\mathrm{C}=$ criança):

\section{[E coloca em cima da mesa dois macacos de brinquedo idênticos]}

E: Agora é a história dos irmãos macaco. A Dona Galinha era muito boazinha, adorava ajudar as pessoas. Quando ela passou e viu os macacos sujos, ela falou assim: 'já sei, eu vou lavar esse macaco aqui' [coloca a galinha ao lado de um macaco]. Ela jogou água e sabão, que ela tinha sempre com ela. Ai ela lavou esse macaco. Então, ela foi no outro macaco [coloca a galinha ao lado do outro macaco]. 'Ah, esse macaco aqui, ele tá muito MOLHADO! Já sei... eu não vou lavar ele não, eu vou secar ele. Vou pegar meu secador' [coloca na mesa um secador 
de brinquedo]. Ela pegou o secador e shhhh [E faz barulho de secador] e secou esse macaco aqui.

E: Então, você lembra o que que aconteceu na história? [tira a galinha da mesa] Agora você escolhe um macaco e fala pro Caco qual macaco você escolheu.

[criança pega o macaco e se dirige ao fantoche]

C: (Eu escolho) o macaco que a galinha secou.

Resultados e discussão

Foi obtido um total de 189 produçóes de oraçóes relativas pelas crianças e 72 pelos adultos. O gráfico a seguir apresenta o percentual de produção de estruturas-alvo, ou seja, sentenças relativas com e sem PRs:

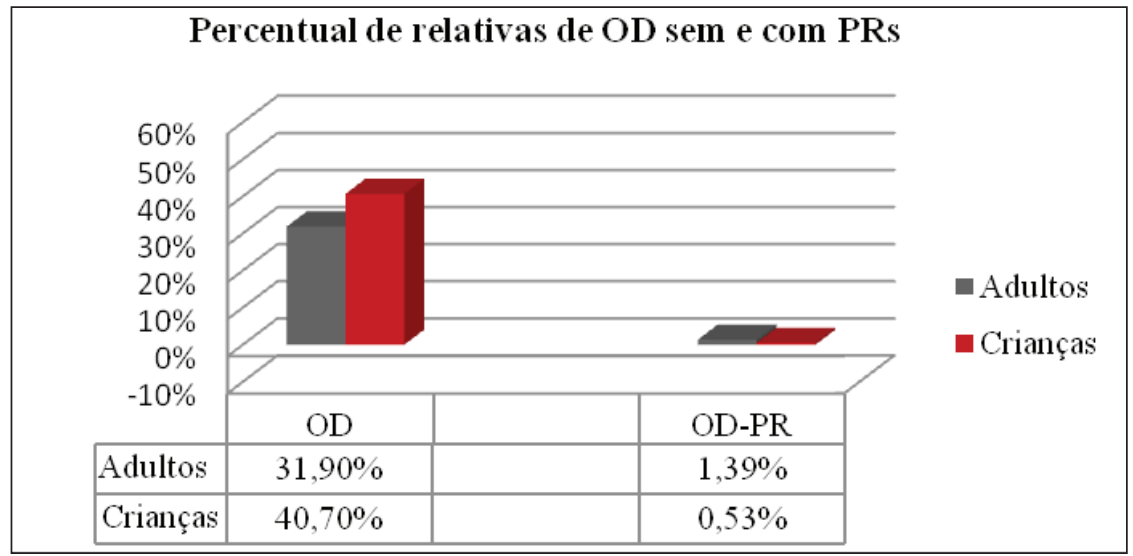

Gráfico 1: Produção de relativas de objeto direto com e sem pronomes resumptivos

Conforme pode ser averiguado pelos percentuais exibidos no gráfico, percebe-se que a produção de oraçóes relativas de objeto direto se limita a um terço das produçóes efetivamente realizadas, não constituindo, portanto, o único tipo de resposta fornecida pelos participantes, mesmo os adultos. Estes mostram preferência pelo uso de oraçóes relativas de sujeito apassivado (ver abaixo), o que confirma resultados obtidos em outros estudos (CORRÊA et alii, (2008) no PB, BELLETTI; CONTEMORI (2010), no italiano). 
(2) A bola que está sendo chutada [pausa] pelo menino. (Fr.)

O uso de PRs também se mostra bastante baixo para os adultos. Vale salientar que as respostas das crianças seguem a mesma tendência dos adultos tanto no que diz respeito ao percentual médio de uso de relativas de objeto quanto de uso de PRs, de modo similar ao que observamos para as crianças adquirindo inglês do estudo de McKee e McDaniel reportado anteriormente.

\subsection{Experimento 2: produção de relativas a partir de figuras}

Nesse experimento ${ }^{7}$, buscou-se verificar se crianças produzem PRs em sentenças relativas de níveis de complexidade distintos. Eliciaram-se relativas de sujeito, objeto direto e genitivas. A variável dependente do experimento é o número de produçóes da estrutura-alvo e, entre essas, o número de produçóes contendo PRs. As variáveis independentes são: tipo de relativa (sujeito, objeto direto e genitivas) e idade (crianças e adultos, como grupo controle).

\section{Método:}

Participantes: Esse experimento foi aplicado a 23 crianças com idades entre 3;5 e 5;11 (idade média 4;3), sendo 3 crianças entre 3;5 e 3;11, dez crianças entre 4;0 e 4;11 e dez crianças entre 5;0 e 5;11 anos. Dez adultos compuseram o grupo-controle.

\section{Material:}

Foram utilizadas figuras contendo um par de imagens com um mesmo personagem em atividades distintas, totalizando 12 figuras-teste, sendo quatro figuras para cada tipo de sentença (sujeito, objeto direto e genitiva). Havia, ainda, 12 figuras distratoras. Um fantoche, de nome Caco, participava da atividade. A seguir, uma das figuras-teste utilizadas no experimento:

7 Os dados desse experimento foram coletados em 2010 e inicialmente analisados em dois trabalhos: Pires (2011a) e Pires (2011b). 

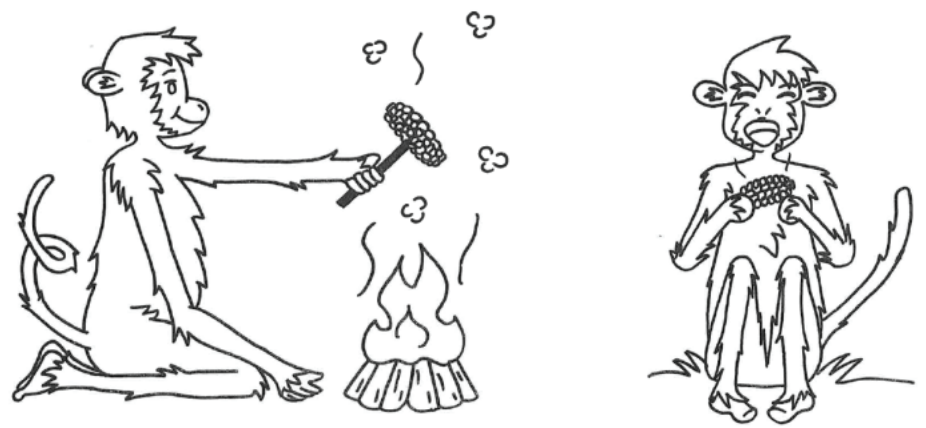

Figura 1: Ilustração utilizada no experimento de produção eliciada

\section{Procedimento:}

As crianças eram convidadas a participar, individualmente, de uma atividade, que consistia na escolha de uma das imagens dispostas em uma figura, na qual a criança deveria colar um adesivo. O fantoche Caco era apresentado como sendo o dono das figuras. As figuras eram sucintamente descritas pelo experimentador, e a criança colava o adesivo na imagem escolhida em cada figura. $\mathrm{O}$ fantoche era mantido com os olhos vendados, e, então, a criança deveria informar qual era a imagem escolhida. Para tanto, esperava-se o uso de uma oração relativa. $\mathrm{O}$ procedimento durava por volta de 30 minutos. A seguir, apresenta-se, a título de ilustração, uma das histórias ( $\mathrm{E}=$ =xperimentador; $\mathrm{C}=$ criança):

E: Veja, a gente tem dois macacos. Aqui o macaco está assando o milho. Aqui, o macaco está comendo o milho. Vamos colar o adesivo no milho e contar para o Caco? Que milho você escolhe?

(a criança cola o adesivo em uma das imagens e se dirige ao fantoche)

C: Eu escolhi o milho que o macaco está comendo.

Resultados e discussão

Os percentuais de produção das estruturas-alvo por adultos e crianças podem ser verificados no gráfico a seguir: 


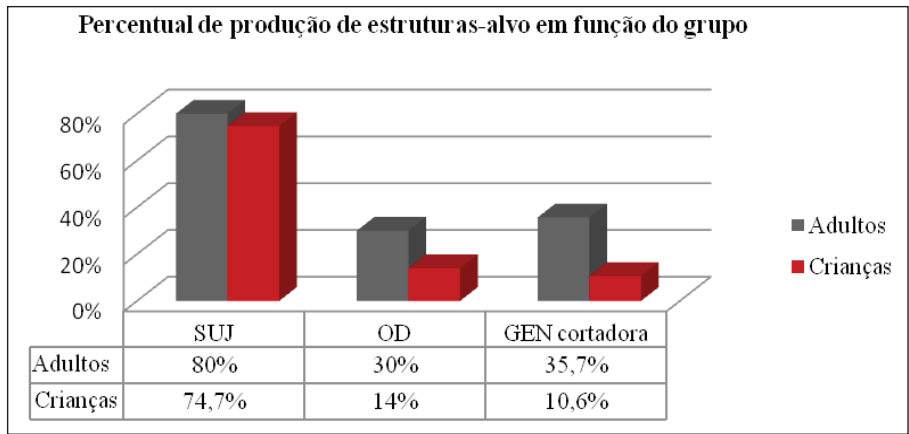

Gráfico 2: Percentual de produção de estruturas-alvo nos adultos e nas crianças

O teste-t indica que há diferenças significativas entre a produção de adultos e crianças para OD ( $\mathrm{p}<0.0498)$ e GEN ( $\mathrm{p}<0.0503)$, mas não em relação à produção de relativas de sujeito. Há diferença significativa entre SUJ e OD/GEN nos grupos, mas não entre OD e GEN.

Conforme já salientado no experimento anterior, o uso de relativas de objeto direto pelos adultos não é muito expressivo, mas percebe-se um uso ainda menos expressivo pelas crianças. $\mathrm{O}$ mesmo pode ser observado em relação às relativas genitivas.

No que diz respeito ao uso da estratégia com PRs na produção das crianças, é possível observar no gráfico a seguir que não há praticamente resumptivos em relativas de sujeito, enquanto o percentual de uso de resumptivos em relativas de objeto e em genitivas ultrapassa um terço das produções (os adultos apresentaram percentuais abaixo de 5\% de PRs):

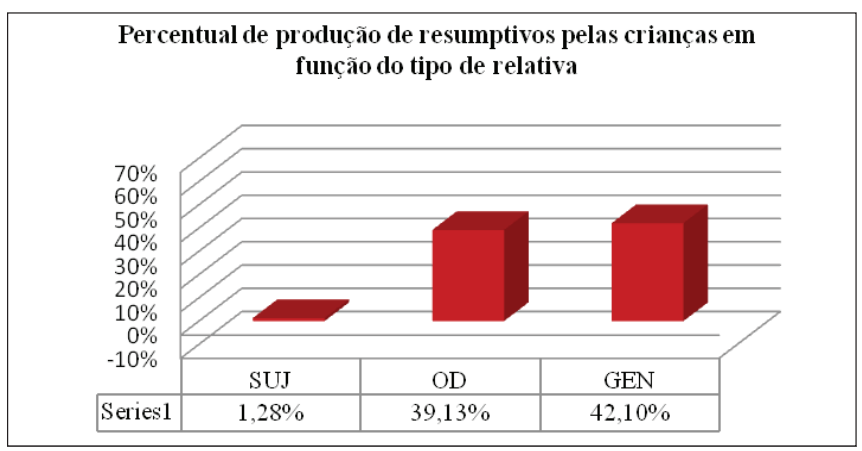

Gráfico 3: Percentual de relativas com pronomes resumptivos (PRs) nas crianças 
É relevante salientar também o tipo de resumptivo utilizado pelas crianças: foram encontrados não só pronomes, mas também sintagmas repetidos, isto é, DPs resumptivos, ocupando a posição da lacuna no interior da estrutura relativa. O gráfico a seguir apresenta os percentuais de tipos de resumptivo utilizados em função do tipo de relativa.

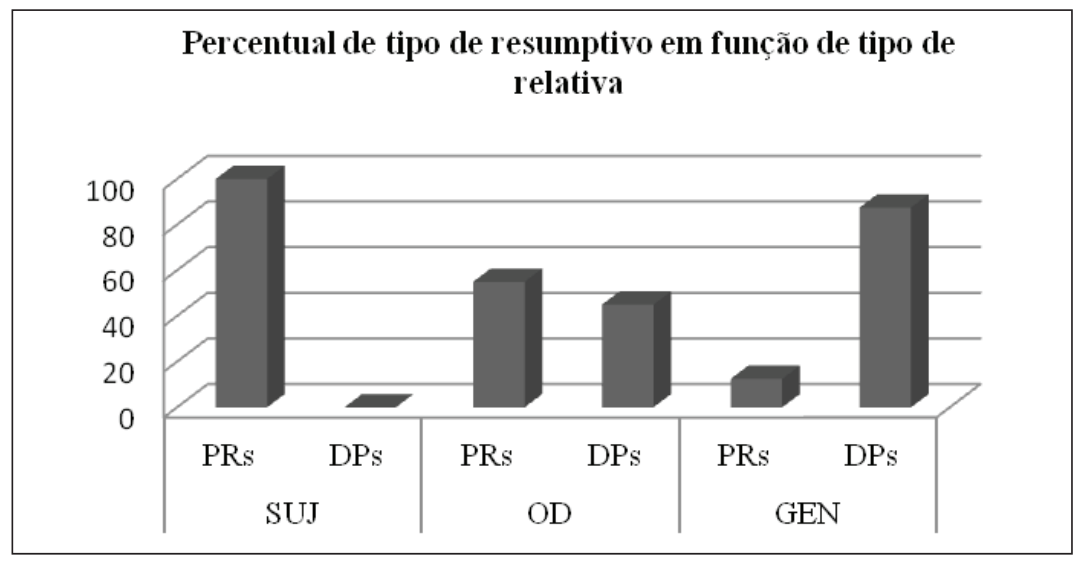

Gráfico 4: Percentual de pronomes resumptivos e DPs resumptivos nas produçóes infantis

Percebe-se que apenas as relativas de sujeito não apresentaram DPs resumptivos. A seguir, um exemplo do uso de PRs nesse tipo de relativa:

(3) A (menina) que ela tá com a banana na mão e comendo a maçã. (Le, 5;6)

O uso de PRs ou DPs resumptivos nas relativas de objeto, ilustrado respectivamente nos exemplos a seguir, foi bastante equilibrado.

(4) $\mathrm{O}$ menino que a menininha tava beijando ele. (Al, 5;0)

(5) O milho que o macaco tá cozinhando o milho (Kai)

Já as relativas genitivas privilegiaram o aparecimento de DPs resumptivos:

(6)A Mônica que a mochila dela tá no chão. $(\mathrm{Al}, 5 ; 0)$

(7) $\mathrm{O}$ menino que o cachorro do menino tá se coçando. (Mat, 5;4) 
Os resultados indicam que há um comportamento distinto das crianças a depender da posição sintática da lacuna de uma estrutura relativa. As crianças se assemelham aos adultos no que diz respeito à produção de sentenças relativas de sujeito, cuja eliciação alcançou percentuais altos. A presença de PRs nesse tipo de estrutura é, por outro lado, bastante inexpressiva. No entanto, em relação a estruturas relativas de objeto direto e de genitivo, seu índice de eliciação é bem mais baixo, enquanto a ocorrência de elementos resumptivos mostra-se bem mais expressiva. Vale salientar, ainda, que não são apenas PRs que são encontrados, mas também DPs resumptivos, conforme apresentado.

\section{Experimento 3: julgamento de valor-verdade - estruturas tópico- -comentário}

Nesse experimento, cujos resultados iniciais foram apresentados em Simini; Augusto (2013), buscou-se verificar se a presença de PRs em estruturas de tópico-comentário facilitariam ou dificultariam a compreensão, utilizando-se uma tarefa de julgamento de valor-verdade a partir de histórias com apoio de figuras. Tomou-se como variável dependente o número de acertos, ou seja, se as crianças julgavam como verdadeiras ou como falsas proposiçóes expressas por meio de estruturas do tipo tópico-comentário, de objeto direto, ora com PRs, ora sem. As variáveis independentes foram: faixa etária (dois grupos de crianças de três e quatro anos e um grupo de adultos, tomados como grupo controle) e tipo de sentença (com PRs e sem PRs), com quatro itens cada.

\section{Método:}

Participantes: Participaram deste experimento 20 crianças, constituindo dois grupos etários. O grupo mais novo era composto por dez crianças com idades entre 3;3 e 4;1 anos (idade média: 3;6) e o grupo mais velho, também composto por dez crianças, apresentava idades variando de 4;7 a 5;8 (idade média: 4;8). Dez adultos compuseram o grupo-controle.

\section{Material:}

Foi montado um arquivo do tipo power-point com figuras referentes a quatro histórias infantis criadas com cinco afirmaçóes cada, referentes a per- 
sonagens da história, sendo quatro estruturas tópico-comentário (com/sem anáfora) e uma do tipo distratora-controle. Foram introduzidas marionetes que interagiam com a criança. Carinhas do tipo feliz/triste eram oferecidas às crianças para que expressassem se os enunciados proferidos pelas marionetes estavam de acordo com a história contada ou não. As histórias foram gravadas e eram tocadas para as crianças, fazendo-se uso de um amplificador de som. Folhas de respostas individuais eram utilizadas pelos experimentadores. Encontra-se a seguir um slide utilizado em uma das histórias apresentadas:

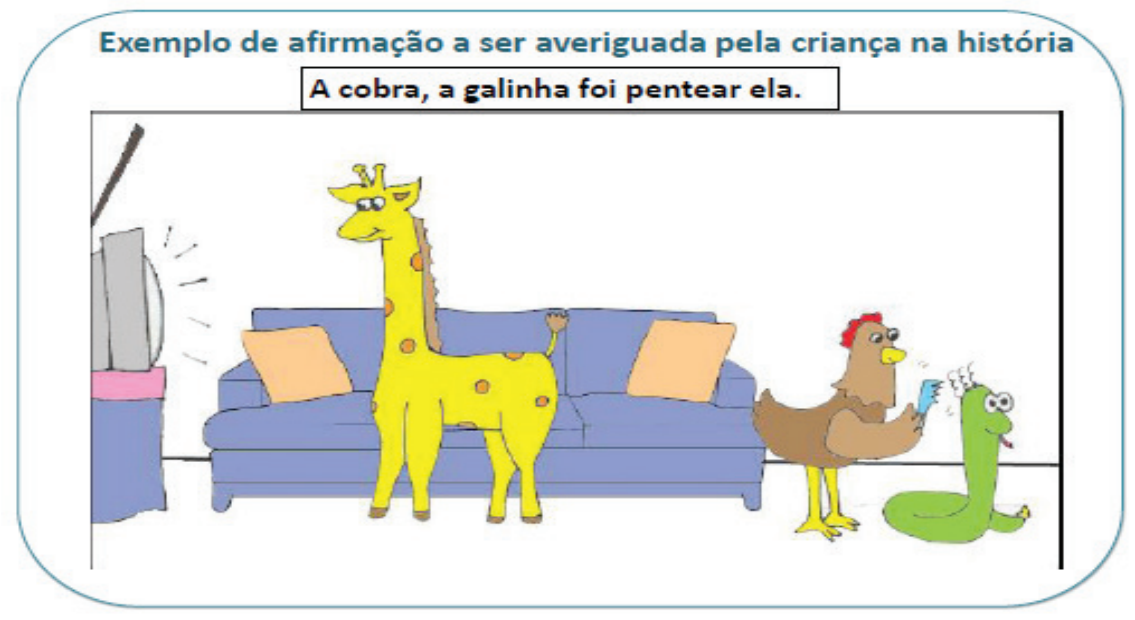

Figura 2: Tipo de ilustração utilizada no experimento de julgamento de valor-verdade

\section{Procedimento:}

As crianças eram convidadas a ouvir histórias contadas no computador em uma sala isolada da escola. Eram apresentadas duas marionetes que também ouviriam as histórias, mas que nem sempre prestavam muita atenção. A tarefa da criança era prestar atenção na história, e, se uma marionete perguntasse à outra sobre o que acontecera na história, a criança deveria confirmar se o que foi respondido havia realmente acontecido, entregando a carinha alegre (o que foi dito acontecera na história) ou a carinha triste (o que foi dito não ocorreu na história) às marionetes. O procedimento levava por volta de 15-18 minutos. 


\section{Resultados e discussão}

Os dados foram submetidos a um ANOVA (2X3), sentenças com ou sem PRs e três grupos etários, considerando-se o grupo controle de adultos. O uso de PRs não afetou o comportamento dos participantes, tendo havido apenas efeito principal de idade $(\mathrm{F}(2,54)=7.95 \mathrm{p}<0.0009)$, distinguindo os adultos das crianças.

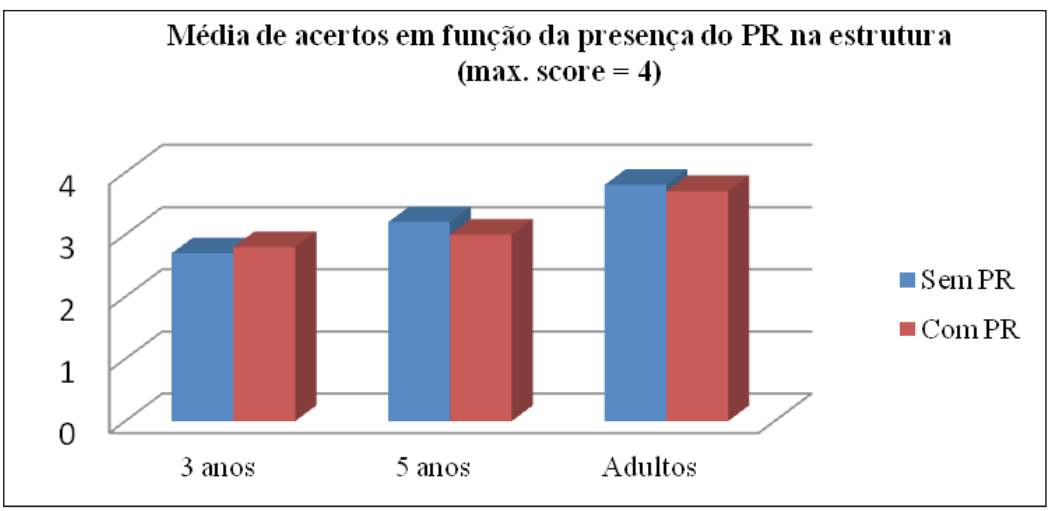

Gráfico 5: Média de acertos em função da presença de PRs

Considera-se, assim, que a presença de PRs não parece influenciar o desempenho da criança na tarefa, qual seja, a de julgar o valor-verdade da proposição expressa pela estrutura tópico-comentário.

\section{Discussão geral}

Os experimentos reportados indicam que o uso de PRs em PB é limitado. No caso da produção, PRs não são amplamente utilizados por adultos, apesar de serem possíveis em diversas posiçóes sintáticas extraíveis (como a posição de objeto direto), diferentemente do inglês, por exemplo, em que se aceitam PRs apenas em posiçôes não extraíveis, como no caso de configuraçóes de ilha sintática. As crianças adquirindo $\mathrm{PB}$ também não lançam mão dessa possibilidade com muita expressividade. É interessante notar, no entanto, que a posição de extração parece ser relevante no que diz respeito ao uso de PRs por crianças. Há pouquíssimo uso de PRs na posição de sujeito, encontrando-se percentuais mais significativos na posição de objeto direto e genitiva. 
Esses resultados parecem indicar que os PRs podem ser tomados pela criança como uma estratégia para facilitar a produção de uma sentença mais complexa, no sentido de que há mais material linguístico a ser processado entre a lacuna (a posição de origem do elemento relatizado) e o núcleo da relativa seguido do pronome relativo. Em termos estruturais, observe-se a comparação entre uma relativa de sujeito e uma de objeto direto no que diz respeito ao montante de material interveniente entre essas posiçóes, a ser processado:

(8) Relativa de sujeito: $\mathrm{O}$ menino que _ abraçou o cachorro.

(9) Relativa de objeto direto: $\mathrm{O}$ cachorro que o menino abraçou

No âmbito da teoria linguística, tem sido apontado que o processamento de orações relativas de objeto, na aquisição, estaria mais sujeito a inadequaçóes do que o de relativas de sujeito (BROWN, 1972; CORREAA, 1995; TAVAKOLIAN, 1981). Mais recentemente, a partir do arcabouço gerativista, Friedman et alli (2009) sugerem que a dificuldade com relativas de objeto é particularmente saliente quando há uma similaridade estrutural entre o elemento relativizado (A'- movido) e o sujeito interveniente, interpretando esse efeito em termos de uma extensão do Princípio de Minimalidade Relativizada (RIZZI, $1990)^{8}$, ao qual as crianças estariam sujeitas.

Corrêa; Augusto (2011) discutem o custo de computação de oraçóes relativas de sujeito e de objeto, buscando verificar como essas questóes de interveniência de elementos podem ser interpretadas à luz de um modelo de processamento - o modelo integrado de computação on-line (MINC, CORRÊA \& AUGUSTO, 2007; 2011), o qual permite considerar o momento da formulação ou do parsing de uma determinada estrutura, o que permitiria prover uma métrica de custo computacional.

De maneira geral, portanto, há resultados e uma discussão na literatura que vêm identificando, na aquisição, maiores dificuldades diante de estruturas mais complexas. Essa complexidade está relacionada à distância hierárquica entre o pronome relativo e a lacuna. Desse modo, prevê-se que relativas de

8 Definição original de Minimalidade Relativizada (Rizzi, 1990: 7) (tradução nossa):

Tomem-se $X$....Z....Y; $X$ rege $Y$ se e somente se não houver um $Z$ tal que: (i) $Z$ é um regente potencial típico de $\mathrm{Y}$, e (ii) $\mathrm{Z}$ c-comanda $\mathrm{Y}$ e náo c-comanda $\mathrm{X}$, (iii) sendo regentes potenciais típicos: núcleos, Spec A, Spec A’. 
sujeito seriam menos complexas que as de objeto direto, estas menos complexas que as de objeto indireto, sendo as genitivas as mais complexas. Nossos resultados, em relação à presença de PRs, parecem sugerir que estes tendem a ser produzidos nas estruturas de maior complexidade.

Acreditamos, assim, que há dois aspectos importantes a serem considerados no que diz respeito à produção de PRs: as demandas do processamento linguístico dessas estruturas, cuja complexidade é distinta para cada tipo de estrutura relativa, e as efetivas possibilidades estruturais fornecidas por cada gramática particular. Comparando-se, assim, os resultados reportados, particularmente os do experimento 2 , com aqueles obtidos por outros pesquisadores em línguas diversas, apresentados na seção 1, percebe-se que as crianças falantes de PB produziram PRs em taxas ligeiramente acima daquelas de crianças falantes de francês ou inglês e mais próximas das de crianças falantes de espanhol (ver Tabela 1). Vale, ainda, salientar que as crianças brasileiras fizeram uso de DPs resumptivos com alguma frequência, particularmente em relativas genitivas, as mais complexas estruturalmente.

$\mathrm{Na}$ comparação intra-língua entre crianças e adultos, fica evidente que há distinçôes. Os adultos produzem menos PRs e não sofrem interferências da presença de PRs para a tarefa de julgamento de valor-verdade, na compreensão. No caso das crianças, embora haja uma produção de PRs mais expressiva do que nos adultos, na compreensão, o $\mathrm{PR}$ não parece ser útil ${ }^{9}$. Conforme foi apresentado na seção 1 , resultados da literatura indicam que as crianças tendem a aceitar PRs, mesmo em contextos agramaticais, em taxas ainda mais elevadas do que tendem a produzi-los. Assim, pode-se esperar plena aceitação dos PRs pelas crianças em estruturas tópico-comentário do PB e um comportamento similar seja diante da presença ou da ausência desses pronomes, na tarefa em questão. Em suma, as crianças não apresentam um comportamento idêntico ao do adulto. Se, por um lado, o PR, na produção, parece exercer algum papel, possivelmente relacionado à demanda de produção de estruturas

9 Nossos resultados com PRs em estruturas tópico-comentário são semelhantes aos obtidos por Miranda (2008) em uma investigação acerca da compreensão de oraçóes relativas de sujeito e objeto com/sem PRs. A autora não obteve, nos dois grupos de crianças investigados, com idades médias de 3;7 e 5;2 anos, diferenças significativas em relação à presença/ausência dos resumptivos. Vale salientar, no entanto, que houve um efeito próximo da significância em relação às crianças mais velhas, sugerindo uma maior dificuldade na presença de resumptivos em relativas de objeto. 
mais complexas; na compreensão, a presença do PR não demonstra ter um papel facilitador. ${ }^{10} \mathrm{O}$ quadro obtido indica, assim, que a produção de PRs e a compreensão deles por parte da criança estão sujeitas a um caminho de desenvolvimento, o qual parece ser condicionado por fatores tanto linguísticos, já que há comportamentos distintos a depender da língua, quanto procedimentais, uma vez que há uma relação entre maiores percentuais de uso de PRs e complexidade estrutural.

\section{Consideraçóes finais}

Este artigo focalizou a produção e compreensão de PRs, apresentando os resultados de três experimentos conduzidos com crianças e adultos falantes nativos de $\mathrm{PB}$. Dois desses experimentos detiveram-se sobre a produção de sentenças relativas, cujo uso de PRs poderia figurar em diversas posiçôes sintáticas. O terceiro experimento focou a compreensão de estruturas tópico-comentário de objeto direto com ou sem PRs. Os resultados sugerem que o uso de PRs em PB é limitado. No caso da produção, PRs não são amplamente utilizados por adultos, apesar de serem possíveis em diversas posiçóes sintáticas extraíveis (como a posição de objeto direto). As crianças também não lançam mão dessa possibilidade com muita expressividade. É interessante notar, no entanto, que a posição de extração parece ser relevante no que diz respeito ao uso de PRs por crianças. Há pouquíssimo uso de PRs na posição de sujeito, encontrando-se percentuais mais significativos na posição de objeto direto e genitiva. Chamou atenção o fato de DPs resumptivos também serem utilizados pelas crianças, com maior expressividade, em relativas genitivas, as de maior complexidade estrutural. Os resultados de compreensão não parecem indicar que a presença de PRs facilite ou dificulte o desempenho das crianças. No entanto, estão ainda em andamento estudos que buscam verificar se a complexidade da estrutura tópico-comentário (objeto indireto, complemento nominal, genitiva) pode ser um fator relevante para uma maior facilitação da compreensão desse tipo de estrutura.

10 Vale salientar que o experimento 3 testou apenas estruturas tópico-comentário de objeto direto. Estudos adicionais fazendo uso de estruturas mais complexas estáo em andamento (MELLO; AUGUSTO, em preparação). 
Em termos gerais, pode-se afirmar que as crianças não apresentam um comportamento idêntico ao do adulto e que os resultados até então obtidos nessa investigação acerca da manifestação de PRs sugerem que o desenvolvimento da criança é condicionado por fatores gramaticais, pois há distinçóes dependentes de língua, assim como por fatores procedimentais, uma vez que a manifestação de PRs na produção parece ser dependente da complexidade que o tipo de estrutura impóe para o seu processamento sintático.

\section{Referências}

BAR-SHALOM, E.; VINNITSKAYA, I. Relative Clauses in Child Russian: a Comparison with Serbo-Croatian. In: M. Rodríguez-Mondoñedo and E. M. Ticio. Storrs (Eds.) UConn Working Papers in Linguistics 12, University of Connecticut, 2004.

BROWN, H. Children's comprehension of relativized English sentences. Child Development 42: 1923-1936, 1972.

CORREA, L.M.S. An alternative assessment of children's comprehension of relative clauses. Journal of Psycholinguistic Research 24, 183-203, 1995.

; AUGUSTO, M.R.A. Computação linguística no processamento on-line: soluções formais para a incorporação de uma derivação minimalista em modelos de processamento. Cadernos de Estudos Linguísticos 49: 167-183, 2007.

Possible loci of SLI from a both linguistic and psycholinguistic perspective Lingua, Elsevier, v. 121: 476-486, 2011.

FRIEDMANN, N., BELLETTI, A. \& RIZZI, L. Relativized relatives: Types of intervention in the acquisition of A-bar dependencies. Lingua: 119: 6788, 2009.

GOODLUCK, H.; STOJANOVIC, D. The Structure and Acquisition of Relative Clauses in Serbo-Croatian. Language Acquisition 5: 285-315, 1996.

GROLLA, E. Pronouns as Elsewhere Elements: Implications for Language Acquisition. Cambridge Scholars Publishing: Newcastle upon Tyne. 2010.

LABELLE, M. Predication et Mouvement: Le Developpement de la Relative chez les Enfants Francophones, Ph.D. Dissertation, University of Ottawa, 1988.

- Predication, Wh-Movement and the Development of Relative Clauses. Language Acquisition 1: 95-119, 1990. 
MCKEE, C.; MCDANIEL, D. Resumptive Pronouns in English Relative Clauses. Language Acquisition 9: 113-156, 2001.

MELLO, F.R.; AUGUSTO, M.R.A. Compreensão de pronomes resumptivos em estruturas tópico-comentário de objeto indireto: primeiras impressóes. Universidade do Estado do Rio de Janeiro, em preparação.

MIRANDA, F. O custo de processamento de oraçóes relativas: um estudo experimental sobre relativas com pronome resumptivo no Português Brasileiro. Dissertação. Pontifícia Universidade Católica do Rio de Janeiro, 2008.

PÉREZ-LEROUX, A. T. Resumptives in the Acquisition of Relative Clauses. Language Acquisition 4:105-138, 1995.

PIRES, A. Aquisição de relativas de objeto: alternância, construçóes absolutas e passivização. VIII ENAL Encontro Nacional sobre Aquisição da Linguagem, 2011 a.

A Produção de Orações Relativas por Crianças Adquirindo Português Brasileiro como Língua Materna. VII Congresso Internacional da ABRALIN, $2011 \mathrm{~b}$.

PIRES, A. \& VIVANCO, K. Um estudo experimental sobre a aquisição de orações relativas no Português Brasileiro. 59 Seminário do Grupo de Estudos Linguísticos do Estado de São Paulo (GEL), 2011.

RIZZI, L. Relativized Minimality. Cambridge, MA: MIT Press, 1990.

TAVAKOLIAN, S.L. The conjoined-clause analysis of relative clauses. In: Tavakolian, S. L. (ed.) Language acquisition and linguistic theory. MIT Press, Cambridge, MA, p. 167-187, 1981.

VARLOKOSTA, S.; ARMON-LOTEM, S. Resumptives and Wh-Movement in the Acquisition of Relative Clauses in Modern Greek and Hebrew. In A. Greenhill (ed.). Proceedings of the 22th Annual Boston University Conference on Language Development, Cascadilla Press: Sommerville, MA, p.737-746, 1998. 


\title{
RESUMPTIVE PRONOUNS IN THE ACQUISITION OF BRAZILIAN PORTUGUESE: PRODUCTION AND COMPREHENSION DATA
}

\begin{abstract}
This article presents the results of three studies which investigated the production and comprehension of resumptive pronouns by children acquiring Brazilian Portuguese as their mother tongue and by adult native speakers of this language. Resumptive pronouns in several syntactic positions were tested and the results suggest that the use of these pronouns in BP is very limited but that the position where the pronoun appears seems to be relevant for its use by children.
\end{abstract}

KEYWORDS: relative clauses; topic-comment structures; resumptive pronouns; gaps; experimental methods.

Recebido em 31/03/14 Aprovado em 05/06/14 